\title{
Des-naturalizando Kuhn
}

\author{
RENAN SPRINGER DE FREITAS
}

$\mathrm{K}$

UHN NOTABLIZOU-SE por seu esforço no sentido de naturalizar a epistemologia. Tal esforço exprime-se na tese amplamente conhecida e aceita de que o progresso científico deve ser explicado examinando-se a natureza do grupo científico e descobrindo-se o que esse grupo valoriza, tolera e desdenha. Apesar da popularidade dessa tese, considero-a equivocada. O próprio Kuhn a contrariou em momentos cruciais de seu A estrutura das revoluções científicas. Neste artigo desenvolve-se o argumento de o legado importante de Kuhn não ser a sociologia do conhecimento que se desenvolveu sob inspiração de sua proposta de naturalizar a epistemologia (ou de converter o conhecimento em um fenômeno sociológico), mas a sua involuntária e negligenciada contribuição para o aprimoramento da epistemologia evolucionária popperiana.

No posfácio de seu $A$ estrutura das revoluções científicas Kuhn afirma que se viesse a reescrever o livro inicia-lo-ia com uma discussão sobre a estrutura comunitária da ciência. Apesar de seus numerosos e sabidos defeitos (1), penso que este livro se encontra bem como está. Falta-lhe, de fato, uma discussão importante, não sobre a "estrutura comunitária da ciência", mas sobre o caráter objetivo e autônomo do conhecimento. Um ano antes de Kuhn publicar o referido posfácio, Popper iniciou tal discussão (2), ao referir-se a um mundo autônomo de produtos da mente humana, notadamente de implicações lógicas de teorias, o chamado mundo 3 , em contraste com o mundo 2 dos pensamentos, valores e crenças humanas (e, portanto, das comunidades científicas), e o mundo $I$ dos objetos materiais.

Popper propôs que o conhecimento, como as espécies, evolui por meio da proliferação e correção de erros, os quais são gerados quando qualquer organismo vivo - de uma ameba a Einstein - tenta resolver problemas. O conhecimento, como a vida, começa com problemas e evolui pelas tentativas de solucionar tais problemas, e da retenção daquelas (relativamente poucas) tentativas que resistem a forças seletivas, seja o ambiente, no caso das espécies, seja a crítica, no caso do conhecimento. Hipóteses, conjecturas e teorias são termos mais familiares para erros e para tentativas de solucionar problemas. Estes termos podem ser legitimamente usados como se fossem intercambiáveis. Segundo Popper, as teorias se sucedem umas às outras no mencionado mundo autônomo de produtos da mente humana, de acordo com o seguinte esquema:

$$
P_{1} \longrightarrow T T \longrightarrow E E \longrightarrow P_{2}
$$


no qual $\mathrm{P}_{1}$ é algum problema original, TT (teoria tentativa) a formulação de teorias que buscam solucionar esse problema, $E E$ a eliminação de erros mediante crítica, e $\mathrm{P}_{2}$ o novo problema, emergente da solução do problema anterior. Nesse esquema, a solução de um problema (TT) carrega consigo novos problemas. Esta é a condição primordial para o avanço do conhecimento.

Neste artigo desenvolvo o argumento de que o legado relevante de Kuhn tem a ver com a sua involuntária e negligenciada contribuição para o aprimoramento do esquema evolucionário citado, e não com o seu empenho em converter o conhecimento científico em um fenômeno sociológico. Para usar os próprios termos de Kuhn, acredito que sua obra é muito mais valiosa se vista como um trabalho de "ciência normal", potencialmente capaz de aperfeiçoar o paradigma evolucionário popperiano (o qual se articula em torno da tese de a evolução do conhecimento ter lugar em um mundo autônomo de produtos da mente humana), do que como o que de fato ela veio a se tornar: uma fonte de inspiração para uma sociologia do conhecimento empenhada em reduzir o conhecimento científico ao que se passa no interior da comunidade científica.

\section{O legado sociológico de Kuhn}

De acordo com Kuhn, são dois os legados que um paradigma pode deixar: alguns problemas (ou "quebra-cabeças", para usar sua terminologia), e uma "ciência normal", isto é, um esforço coletivo no sentido de resolver esses problemas. Que problemas e que "ciência normal" o pensamento kuhniano nos legou? Pelas minhas contas, os problemas são dois, e a ciência normal é nenhuma. Antes de mencionar esses problemas, entretanto, devo lembrar que há todo um conjunto de problemas que não são um legado kuhniano. Desde Manheim, Merton e Polanyi a sociologia do conhecimento ocupa-se do problema da recepção de teorias, o qual se traduz em questões do tipo "por que o darwinismo nunca foi bem aceito na França", ou "por que a genética mendeliana foi negligenciada por quase 30 anos?", entre outras. Os problemas que Kuhn nos legou são de outra ordem.

Em um plano imediato, sua teoria (candidata a paradigma) de que a ciência evolui de acordo com o esquema:

$$
\text { paradigma } \longrightarrow \text { ciência normal } \longrightarrow \text { crise } \longrightarrow \text { novo paradigma }
$$

levanta o problema da relação entre crise e revolução científica. Este problema traduz-se em "quebra-cabeças" do tipo "como diferenciar uma crise de uma mera anomalia?", ou "como medir a extensão de uma crise?" ou, ainda, "que crise conduziu à emergência da, digamos, teoria da seleção natural?” Até onde sei, nenhum grupo de sociólogos ou de filósofos da ciência debruçou-se sobre tais "quebracabeças" - talvez por não serem bons "quebra-cabeças". Não tenho, por exemplo, conhecimento de livro ou artigo que tenha tomado o livro A revolução copernicana (o qual levou Kuhn a introduzir a noção de paradigma) como modelo para explicar alguma outra revolução científica. Tampouco tenho conhecimento de algum tra- 
balho que tenha tomado a discussão de Kuhn sobre, digamos, a emergência da teoria da combustão como modelo para explicar a emergência de alguma outra teoria (3). Somente em estudos dessa natureza os "quebra-cabeças" mencionados poderiam ser enfrentados. Tenho conhecimento de uma coletânea cujas colaborações discutem a relação entre anomalias e revoluções, mas isto é muito pouco para constituir o que Kuhn chama de ciência normal (4). Daí, a tese central de Kuhn, a de que o conhecimento científico evolui de acordo com o esquema apresentado, não nos legou ciência normal alguma.

Não obstante, sua tese teve um impacto enorme. Ela inspirou uma verdadeira legião de sociólogos, e isto não chega a ser surpreendente. Afinal, ao formular a tese, Kuhn vinculou a natureza do conhecimento científico aos valores e critérios de decisão adotados pelos membros da comunidade científica, e associou revoluções científicas a mudanças de compromissos e de crenças comunalmente partilhados. Kuhn foi, portanto, muito mais longe do que a sociologia do conhecimento jamais se permitiu ir. Nunca, antes dele, se concebeu um convite tão enfático para uma sociologização do conhecimento.

A questão, entretanto, está em saber até onde se pode ir aceitando-se este convite. Pelo que consigo perceber, pode-se chegar às seguintes teses:

a) evidências empíricas são insuficientes para resolver impasses relativos à aceitação de teorias porque escolhas de teorias dependem mais dos modos pelos quais os cientistas são socializados do que da adequação empírica das teorias em competição;

b) os cientistas resistem a teorias que contrariam as crenças e interesses dos grupos aos quais pertencem sem se preocupar em saber se estas teorias exibem ou não um poder explicativo comparativamente elevado;

c) os cientistas adaptam suas concepções às exigências de seu ambiente sociopolítico (5);

d) fatores extra-cognitivos podem ajudar a derrubar uma teoria (6).

Estas teses devem muito a Kuhn, e os trabalhos empíricos que se movem em torno delas atingiram uma proporção epidêmica - o periódico Social Studies of Science destina-se quase que exclusivamente à publicação de tais trabalhos (7). Estes trabalhos, porém, não chegam a constituir uma ciência normal no sentido kuhniano. Ciência normal envolve empenho em resolver alguns problemas e, até onde minha vista alcança, tais trabalhos não se debruçam sobre problema algum. Eles recorrem a estudos de caso para corroborar ou ilustrar as teses referidas, o que é sem dúvida interessante, mas nada tem a ver com tentar resolver algum "quebracabeça".

O segundo problema que Kuhn nos legou é um “quebra-cabeça” implicado por uma tese que, por assim dizer, encontra-se na raiz de seu convite à sociologização do conhecimento e, por extensão, das teses "a" a "d" citadas. Trata-se da tese de 
que o conhecimento científico tem um caráter social e historicamente contingente. Se, como diz Kuhn, decisões contingentes e compromissos assumidos no interior da comunidade científica fazem parte da natureza do conhecimento científico, e se essas decisões e esses compromissos poderiam ter sido outros se as circunstâncias históricas e sociais nas quais as comunidades científicas se estabeleceram e se desenvolveram tivessem sido outras, então o conhecimento científico tal como hoje o conhecemos poderia ter sido outro. Um eco bastante visível desta tese está na afirmação de Steve Fuller, de que a ciência contemporânea "is merely the product of following one of several paths that had been equally open at an earlier point in our history" (8). O problema ou "quebra-cabeça" que esta tese obviamente levanta é o seguinte: se a ciência contemporânea poderia ter sido outra, então deve haver alguma ciência alternativa. No mínimo, deve haver algum registro de alguma ciência alternativa que em algum momento do passado se extinguiu por razões de ordem sociológica - da mesma forma que há registros de religiões que se extinguiram no passado por razões de ordem sociológica (9). Que ciência alternativa é esta? Pelo que sei, David Bloor é o único sociólogo que se debruçou sobre este "quebra-cabeça", ao tentar mostrar que pode haver uma matemática alternativa (10). Mas, este louvável, solitário, e muito mal-sucedido (11) esforço não é também suficiente para constituir uma ciência normal.

Daí que o legado do pensamento kuhniano, se visto como um paradigma sociológico, é muito pequeno ou mesmo insignificante. De acordo com o próprio Kuhn, o mínimo que se pode requerer de um paradigma é que gere, junto com alguns problemas, alguma ciência normal, e este último requisito não foi satisfeito. A proporção epidêmica de trabalhos que, apoiando-se na obra de Kuhn, explora as teses "a" a "d" anteriormente mencionadas, deixa "quebra-cabeças" centrais do pensamento kuhniano (tais como: em que circunstâncias uma anomalia gera crise? ou, como distinguir uma ciência normal de uma ciência extraordinária? ou, ainda, que ciência alternativa ficou impedida de se desenvolver por razões de ordem sociológica?) no mesmo ponto em que Kuhn os deixou em 1962. O legado importante do pensamento kuhniano não está portanto na sociologia do conhecimento que se desenvolveu sob sua inspiração. Talvez ele esteja em outro lugar.

\section{O legado não-sociológico de Kuhn}

Kuhn propôs a conversão do conhecimento científico em um fenômeno sociológico ao vincular a natureza desse conhecimento à "estrutura comunitária da ciência". Felizmente tal proposta se choca com as discussões substantivas que ele apresenta em A estrutura das revoluções científicas. A densidade deste livro é impressionante e não há como lhe fazer justiça nos limites de um artigo como este. Detenhome na discussão de Kuhn sobre as limitações da mecânica newtoniana se comparada à einsteiniana, e de sua explicação para a emergência da teoria da eletricidade de Franklin, da teoria da combustão de Lavoisier, e da teoria atômica de Dalton. Não há mérito em multiplicar os exemplos. Não descarto a possibilidade de ter omitido exemplos melhores, ou de ter explorado mal os exemplos aleatoriamente escolhidos. 
Ao debruçar-se sobre os temas que acabo de mencionar, e sobre muitos outros, o que Kuhn no fundo mostra é que a compreensão desses temas prescinde de qualquer sociologia do conhecimento. A mecânica newtoniana é limitada porque é incapaz de lidar com efeitos relativísticos. As três teorias mencionadas são correções de teorias anteriores. A teoria de Franklin elevou-se ao status de paradigma porque Franklin conseguiu explicar a atração e a repulsão ao mesmo tempo, enquanto seus antecessores só explicavam uma coisa ou outra (12). A teoria da combustão de Lavoisier apareceu para resolver um problema gerado por uma teoria da combustão anterior, a de Priestley. De acordo com esta última, corpos em combustão deveriam perder peso, e o que na verdade ocorre é o oposto (13). Dalton corrigiu dois químicos franceses - Prous e Berthollet - ao formular sua teoria de que os átomos só podem se combinar numa proporção de um por um ou em alguma outra proporção de números inteiros (14). A informação adicional de Kuhn de que Berthollet reagiu energicamente a Dalton é irrelevante para o entendimento da evolução da química, e Kuhn mostra-se ciente disto.

Por outro lado, ao tentar converter o conhecimento científico em um fenômeno sociológico, Kuhn obscureceu a real importância do papel dos paradigmas e da ciência normal na evolução da ciência. Tal conversão envolve vincular estas duas noções ao que os cientistas pensam, sentem, acreditam, falam e fazem. Mas, para a felicidade de A estrutura das revoluções científicas e do conhecimento sobre o conhecimento científico, Kuhn sistematicamente contrariou sua sociologia do conhecimento e deixou de fazer tal vinculação. Sua discussão substantiva o forçou a desvincular o conhecimento científico tanto das crenças e valores dos cientistas quanto da "estrutura comunitária da ciência".

Assim, logo no início do primeiro capítulo de $A$ estrutura das revoluções cientificas, Kuhn desfere dois golpes mortais contra a sua sociologia do conhecimento. O primeiro é ao explicar, em termos de suas "realizações sem precedentes", o caráter paradigmático de obras como A física de Aristóteles, O almagesto de Ptolomeu, os Principia e a Optica de Newton, a Eletricidade de Franklin e a Geologia de Lyell. O segundo, e mais importante, é ao propor, popperianamente, que as referidas realizações deixam em aberto alguns problemas para serem resolvidos posteriormente. O apelo a "realizações sem precedentes" e a problemas gerados autonomamente só se justifica nos marcos de um paradigma que postula, a Popper, a existência de um conhecimento autônomo. Uma sociologia do conhecimento de inspiração kuhniana não pode se viabilizar fazendo concessão a tal postulado (a sociologia do conhecimento convencional pode fazer tal concessão porque limita suas ambições à recepção de teorias e não procura converter a natureza dessas teorias em um fenômeno de caráter sociológico). Se há conhecimento autônomo, isto é, se há produtos da mente humana cujas implicações independem tanto de quem os produziu quanto das maneiras pelas quais eles foram produzidos e descobertos, então esse conhecimento é uma força seletiva à qual tudo aquilo que a sociologia do conhecimento de inspiração kuhniana quer trazer para um primeiro plano (os compromissos dos cientistas com determinadas crenças e valores, a "es- 
trutura comunitária da ciência" etc.) tem de se adaptar. Para viabilizar suas teses sociológicas de que a natureza do conhecimento científico reside na estrutura comunitária da ciência, e de que paradigmas são uma forma de compromisso social, Kuhn teria então de se mover no sentido oposto ao que se moveu. Por um lado, ele teria de se empenhar em mostrar que nenhuma das obras por ele mencionadas se impuseram por seus méritos intrínsecos. Ele teria de tentar mostrar que interesses, convenções e valores adotados em comunidades científicas determinadas fizeram e fazem desses livros (ou de quaisquer outros) o que são (15). Em resumo, para manter-se consistente com sua sociologia, Kuhn teria, num certo sentido, de subscrever o tão popular quanto primário slogan pós-moderno de que o leitor (no caso a comunidade) faz o livro.

Por outro lado, Kuhn também não poderia admitir que as obras mencionadas trazem consigo alguns problemas, porque sua sociologia do conhecimento o proíbe de admitir a existência de problemas (e de soluções de problemas) fora de uma autoridade social (a da comunidade científica) que os reconheça como (ou os converta em) tais. Ao (sabiamente) se esquecer da autoridade do grupo científico no momento em que sua sociologia mais precisava dela, Kuhn comprometeu esta última irremediavelmente. Afinal, qual é o sentido de se debruçar sobre a "estrutura comunitária da ciência" se problemas e soluções de problema emergem e se sucedem sem o seu concurso? Qual é o sentido de examinar tal estrutura se ela é o resultado de um processo seletivo que se passa fora dela? Por que não se deter neste processo seletivo, ao invés de se concentrar em um de seus resultados?

Quando se faz, como Kuhn acabou fazendo, concessão à tese de que a "estrutura comunitária da ciência" se desenha a partir de processos seletivos determinados (tal concessão é inevitável quando se aceita a possibilidade da existência de problemas genuínos e de soluções genuínas), o caminho que naturalmente se abre é o de se debruçar sobre tal processo seletivo. Este foi, em última análise, o caminho que Kuhn clandestinamente trilhou em seu A estrutura das revoluções cientificas, em todos os (bons) momentos em que não tratou nem os paradigmas, nem a ciência normal, como categorias sociológicas; em todos os bons momentos em que bravamente resistiu ao "canto de sereia da sociologia", para tomar a feliz expressão de Peter Munz (16). Deixo em aberto a questão de quantos e de quão bons são esses bons momentos. Nos parágrafos precedentes mencionei uns quatro, e a discussão sobre Dalton (p. 168-169) parece-me particularmente um desses momentos.

Qual é o legado desses bons momentos de Kuhn, isto é, deste Kuhn que desvincula os paradigmas e a ciência normal da autoridade de grupos ao se debruçar sobre questões substantivas, como explicar o caráter paradigmático de a Química de Lavoisier ou a emergência da teoria química atômica de Dalton?

Se, conforme argumentei na seção anterior, a obra de Kuhn não leva a muito longe se vista como um paradigma, talvez ela possa ser valiosa se considerada como um trabalho de ciência normal, isto é, como um trabalho que ajuda a resolver 
"quebra-cabeças" deixados em aberto por algum outro paradigma e/ou a articular melhor os conceitos e teorias deste outro paradigma. Pelo que foi visto anteriormente, um paradigma em cujos termos a contribuição de Kuhn pode revelar-se promissora seria aquele que se articula em torno da tese de que o conhecimento científico se desenha pouco a pouco a partir de um processo seletivo. Ora, este processo seletivo é exatamente o processo que o paradigma popperiano descreve através de seu já mencionado esquema evolucionário

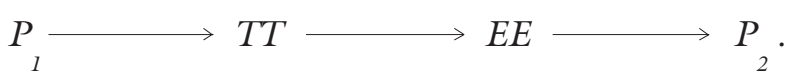

Isto nos traz de volta ao ponto de partida: em que o pensamento kuhniano pode corrigir ou aperfeiçoar este esquema?

A resposta para esta pergunta depende da resposta para uma pergunta anterior: o que há para ser aperfeiçoado ou corrigido no esquema? O esquema tem um problema cuja raiz está na explicação de Popper para a eliminação de erros. De acordo com Popper, erros são eliminados via busca consciente de contradições. Eliminamos erros ao tentar derrubar teorias. Daí o problema: por que esforços no sentido de corrigir uma solução para um problema conduzem a um novo problema (17)? Em outras palavras, o esquema acima não especifica a relação entre $E E \mathrm{e}$ $P$. A eliminação de erros pode tanto conduzir a um novo problema quanto tambẻm não conduzir a nada. $\mathrm{O}$ que faz a diferença?

Parte de resposta pode ser: a qualidade de TT, ou seja, da solução do problema anterior. Nesse ponto, a noção kuhniana de paradigma pode, talvez, lançar alguma luz. Se a referida solução for suficientemente rica em implicações, ela sempre deixará algumas implicações para serem exploradas e, portanto, problemas. Em outras palavras, uma solução de problemas deixará questões em aberto se não for uma solução qualquer (TT), mas apenas se for uma solução paradigmática. Nessa perspectiva, a noção de paradigma substitui com alguma vantagem a noção de TT porque chama a atenção para o fato de haver teorias tentativas que contribuem para a emergência de novos problemas com mais eficiência do que outras. Mas não sei até que ponto tudo isto já não está contemplado no pensamento de Popper, e nem vale a pena me engajar em um exercício desta natureza. Essa parte da resposta não é a mais importante, porque ela deixa em aberto a questão: como a eliminação dos erros de uma solução de um problema (seja esta solução paradigmática ou não) conduz a novos problemas?

No que concerne à questão, a noção kuhniana de ciência normal, se tornada um elemento do mundo 3 popperiano, tem um bom serviço a prestar. Acredito que esta noção constitui de fato um passo adiante.

Penso que Kuhn obscureceu a importância tanto da noção de ciência normal, quanto da noção de paradigma, ao afirmar que a ciência normal envolve compromisso com algum paradigma (18). É verdade que a ciência normal explora as potencialidades de um paradigma, mas explorar potencialidades nada tem a ver com estabelecer e honrar compromissos. Um cientista normal honra seu compro- 
misso com o paradigma em que foi socializado (e, nessa medida, é mesmo digno de pena, como diz Popper), mas tal compromisso não se transfere necessariamente para a ciência normal porque o cientista normal não pode ter controle sobre as implicações de sua ciência. Um trabalho com pretensões modestas pode revelar-se inovador ou trazer contribuições inesperadas. Uma vez aceita a tese da autonomia do conhecimento, a ciência normal deixa de ter direção: se o que ela faz é explorar implicações, e se ninguém tem controle sobre implicações, então ela pode tanto fortalecer quanto debilitar o paradigma que a legou. Penso que é disto que Kuhn está falando quando afirma que "a teoria de Maxwell, apesar de sua origem newtoniana, acabou produzindo uma crise no paradigma do qual emergira" (19).

Em tese, a ciência normal não tem direção nem mesmo quando se resume à uma atividade rotineira tal como aprimorar uma técnica porque, conforme o próprio Kuhn admitiu, um trabalho aparentemente rotineiro pode ter implicações que extravasam em muito os limites do paradigma que o inspirou, podendo até mesmo debilitar tal paradigma. Nesta perspectiva, a ciência normal não requer a aquiescência à autoridade de convenções e/ou de crenças institucionalizadas (Popper pode continuar a ter pena do cientista normal mas não precisa mais temer a ciência normal); ela não requer a "fidelidade a uma tradição", para retomar uma expressão de Kuhn (veja-se nota 18), mas apenas a existência de potencialidades a serem descobertas e exploradas.

Se a ciência normal não tem direção, então ela pode ser vista como o processo que responde pela eliminação de erros $(E E)$. Isso corrigiria um erro de Popper. Essa noção ajuda a entender que a possibilidade da eliminação de erros reside na própria descoberta e exploração das potencialidades de um paradigma, e não em esforços conscientes no sentido de derrubar teorias ou paradigmas. Mais: se a eliminação de erros reside na própria exploração das potencialidades de um paradigma, e se novos problemas são uma dessas potencialidades, então deixa de ser um mistério que novos problemas $\left(P_{2}\right)$ possam emergir de processos de eliminação de erros $(E E)$.

Em face do exposto, ao contrário do que Kuhn supõe, o elo de ligação entre um paradigma e uma ciência normal não é a socialização do cientista, mas o próprio conjunto de potencialidades que o paradigma oferece. Um cientista pode explorar as potencialidades de um paradigma (pode portanto fazer uma "ciência normal") e, assim, contribuir para seu aperfeiçoamento, sem ter sido socializado neste (ou sem ter qualquer compromisso com este) paradigma. Acredito aliás ser este o caso de Kuhn que, ao admitir a emergência autônoma de problemas, faz uma "ciência normal" popperiana sem ter sido socializado na tradição popperiana e sem ter qualquer compromisso com esta tradição. Significa que é no conjunto de potencialidades de um paradigma, e não na sua capacidade de atrair adeptos, ou de forjar compromissos, que reside o seu verdadeiro legado (ou o legado desta "teoria tentativa", para usar a terminologia popperiana).

Kuhn disse algo parecido ao mencionar que paradigmas encerram uma "promessa" que a ciência normal atualiza. Entretanto, essa imagem é num certo sentido 
enganadora, porque supõe ser possível saber de antemão que "promessa" é esta e como cumpri-la. Em face do que expus até aqui, seria mais apropriado dizer que tal promessa, se houver mesmo alguma, se desenha pouco a pouco, na medida que opera a autônoma força seletiva da ciência normal. Isto permitiria entender que a sociologia do conhecimento de inspiração kuhniana não ajuda a desenhar a promessa kuhniana (talvez por não haver mesmo alguma promessa a ser desenhada), ao passo que o pensamento khuniano, que se desenvolveu à margem do paradigma popperiano, e muitas vezes como uma alternativa a este paradigma, ajuda a desenhar a promessa popperiana de explicar a evolução do conhecimento como uma extensão da evolução biológica, ao explorar, ainda que clandestinamente, as potencialidades da tese de o conhecimento evoluir por proliferação e correção de erros.

\section{Conclusão: ciência normal, comunidade científica e evolução do conhecimento}

Em face do exposto, a obra de Kuhn pode ser lida como tendo duas coisas a dizer sobre a tese acima. A primeira é que a proliferação de erros se conforma às restrições impostas por paradigmas ou referenciais teóricos. Desconhecer esse ponto implicaria retornar ao indutivismo positivista que Popper deixou para trás há mais de 60 anos. A segunda é que a correção de erros, e por esse meio o desenho da promessa embutida em uma paradigma, se faz via ciência normal - ou seja, via exploração das potencialidades dos paradigmas.

Quanto ao primeiro ponto, acredito não haver nada mais para se dizer. Quanto ao segundo, entretanto, há de se lamentar que Kuhn não o tenha tomado em conta nas páginas finais de $A$ estrutura das revoluções científicas, quando expõe as analogias entre a sua teoria e a teoria darwiniana da evolução. Na página 215 ele afirma que teorias são selecionadas (ou erros são corrigidos) no interior da comunidade científica. Mas esqueceu-se de dizer que a comunidade científica tem de saber selecionar muito bem, pelo menos bem o suficiente para não ser varrida por outro processo seletivo, a saber, o mesmo processo seletivo que ele implicitamente admitiu ter operado para converter livros tais como $A$ eletricidade, $O$ almagesto etc., em obras paradigmáticas.

Daí resulta que o importante não é a "comunidade científica” em si, mas o processo seletivo ao qual ela está sujeita. Um apelo particularmente infeliz de Kuhn à comunidade científica se acha, na minha opinião, nas últimas linhas do posfácio, nas quais se lê: "O conhecimento científico, como a linguagem, é intrinsecamente a propriedade comum de um grupo ou então não é nada. Para entendê-lo, precisamos conhecer as características essenciais dos grupos que os criam e utilizam".

Quero concluir este artigo argumentando que o conhecimento científico tem de fato de ser criado e utilizado mas, sobretudo, tem de ser retido, da mesma forma que algumas características do grupo científico só se tornam essenciais porque são, de alguma forma, retidas. O processo seletivo que responde tanto pela 
forma que o conhecimento científico assume, quanto pelas caracteristicas essenciais do grupo científico é, portanto, muito mais importante do que estas características essenciais em si mesmas. Nesta perspectiva, querer explicar o conhecimento científico em termos dos processos (sejam sociais, sejam de quaisquer outra ordem) responsáveis por sua criação é como querer explicar a evolução das espécies em termos dos processos responsáveis por variações em organismos individuais, sem levar em conta que só uma proporção ínfima destas variações são retidas por um autônomo processo seletivo. Talvez o desconhecimento desse ponto seja o principal defeito da sociologia do conhecimento de inspiração kuhniana, a qual tem em David Bloor, Barry Barnes, Bruno Latour e, em franca ascensão, Steven Shapin, os nomes mais expressivos. Todos estes autores raciocinam como se Darwin nunca tivesse existido. Kuhn procura não cometer este erro ao tentar mostrar, nas últimas páginas de A estrutura das revoluções científicas, o caráter darwiniano de sua discussão. Pena que, nesse ponto, sua sociologia (ou talvez sua inclinação wittgensteiniana) o tenha atrapalhado, a ponto de impedi-lo de traçar a analogia corretamente, isto é, a ponto de impedi-lo de perceber que, livre de sua conotação sociológica, a "ciência normal" está para a evolução do conhecimento como o ambiente está para a evolução das espécies. $\mathrm{O}$ ambiente explora potencialidades de soluções de problema encarnadas em organismos (soluções tais como o sistema nervoso, os pulmões, os espinhos, os chifres, as unhas planas ou curvas, as barbatanas etc.) e retém as potencialidades e soluções que permitem a organismos vivos ampliar sua prole. Ao fazê-lo, ele desenha, pouco a pouco, a forma que as espécies vêm a assumir. $\mathrm{O}$ mesmo raciocínio se aplica para a ciência normal. Ela explora potencialidades de soluções de problema não encarnadas em organismos (soluções como a teoria eletromagnética de Maxwell, a teoria da combustão de Lavoisier, entre outras), e retém as potencialidades que permitem a tais soluções (ou teorias) ampliar sua prole, ou seja, dar lugar a novos problemas e, portanto, a novas teorias. Ao fazê-lo, ela desenha, pouco a pouco, o formato que o conhecimento científico vem a assumir.

Notas

$1 \mathrm{O}$ defeito mais grave é talvez a pretensão de derivar uma epistemologia a partir da história da ciência. Um segundo defeito é alinhar-se à tese de que significados são relativos a paradigmas. Um terceiro é tomar a não-discussão dos fundamentos como sinal de maturidade. Um quarto está nos equívocos factuais relacionados às suas histórias. Peter Munz (Our knowledge of the growth of knowledge. London, Routledge and Kegan Paul, 1985) ocupou-se do primeiro defeito. D. Shapere (Meaning and scientific change. In Scientific revolutions, Rom Harré (ed.), 1981, p. 28-59) e L. Laudan (Progress and its problems. Berkeley/Los Angeles, University of California Press, 1977) ocuparam-se do segundo. Laudan (citado) e J. Agassi (Science and society. Studies in the sociology of science. Dordrecht, Reidel Publishing Company, 1981) ocuparam-se do terceiro e do quarto. Fico por aqui. É uma pena que em seu badalado livro Reconstructing scientific revolutions (The University of Chicago Press, 1993), Paul Hoyningen-Huene ignore tão ostensivamente estas críticas. 
2 Em um artigo intitulado Epistemology without a knowing subject, originalmente publicado nos Anais do III Congresso Internacional de Lógica, Metodologia e Filosofia da Ciência, em 1968, e republicado em Objective Knowledge, Londres, 1972, p. 106-152.

3 Evidentemente, o fato de eu não ter conhecimento não significa que tais estudos não existam. De qualquer modo, Paul Hoyningen-Huene, em seu já citado Reconstructing scientific revolutions, deu-se ao trabalho de listar a bibliografia secundária com relação a Kuhn. Ele listou mais de 400 títulos e nenhum deles aponta para discussões como as que acabo de mencionar.

4 O nome da Coletânea é Paradigms and revolution, organizada por Gary Gutting (Notre Dame, 1980). A propósito, um dos artigos desta coletânea, Kuhnian paradigm and darwinian revolution, de John C. Grene, procura mostrar que a revolução darwiniana não dependeu de "crise" alguma.

5 A ilustração mais eloqüente desta tese está no famoso artigo de Paul Forman, Weimar culture, causality and quantum theory, 1918-1927. Adaptation by German physicists and mathematicians to a hostile intellectual environment. Historical Studies in the Physical Sciences, n. 3, p. 1-115, 1971.

6 O artigo de Farley \& Geison, citado na nota 15, é o exemplo mais eloqüente de trabalho que ilustra esta tese. Ele procura mostrar que fatores de ordem política ajudaram a derrubar a teoria da geração espontânea. Isto bem pode ser verdade. Mas, evidentemente, é irrelevante, se se trata de saber se esta teoria é válida ou não.

7 Eu desenvolvo este ponto em meu artigo Construtivismo e ironia sociológica, Novos Estudos, Cebrap, n. 36, p. 223-233, jul. 1993.

8 Steve Fuller, Can science studies be spoken in a civil tongue? Social Studies of Science, v. 24, n. 1, p. 143-168, 1994, p. 147. Esta tese é moeda corrente na sociologia da ciência das últimas décadas.

9 Tanto quanto a ciência, a religião procura oferecer respostas para problemas determinados. Toda religião procura, por exemplo, explicar a relação entre mérito e destino. De acordo com Max Weber, todas as grandes religiões que hoje conhecemos venceram, em algum momento do passado, uma acirrada disputa contra alguma religião alternativa - que acabou por se extinguir (Veja-se R. Bendix, Weber, an intelectual portrait, London, MacMillan, 1977, cap. X). Para tanto, elas contaram com a sua capacidade de explicar o infortúnio mas, sobretudo, com a existência de segmentos sociais interessados em difundir suas doutrinas por toda uma civilização. Assim, uma casta de letrados cultos difundiu o hinduísmo, o budismo foi propagado pelos monges e o islamismo pelos guerreiros. Religiões que não conseguiram encontrar portadores suficientemente robustos acabaram por se extinguir. Uma sociologia do conhecimento genuinamente kuhniana teria de expandir tal raciocínio para a ciência, no sentido de apontar alguma ciência que veio a ser extinta em razão de não encontrar portadores no interior da comunidade científica. Teria de mostrar, por exemplo, que houve alguma física alternativa à física newtoniana que só não prosperou porque não encontrou na comunidade científica grupos interessados em propagá-la.

10 Bloor, D., Knowledge and social imagery, London, Routledge and Kegan Paul, 1976.

11 Veja-se a crítica de G. Freudhental, How strong is Dr. Bloor's "Strong Programme"? In Studies in History and Philosophy of Science, v. 10, n. 1, p. 67-83, 1979. 
12 A estrutura das revoluções científicas. São Paulo, Perspectiva, p. 34.

13 Id., ibid., p. 99-100.

14 Id., Ibid, p. 168-169.

15 Kuhn não levou sua tese a tão longe mas houve quem o fizesse por ele. Em um artigo intitulado Science, politics and spontaneous generation in nineteenth century, France: the Pasteur-Pouchet debate (Bulletin of the History of Medicine, n. 48, p. 161-198, 1974), Farley \& Geison argumentam que Pasteur não se impôs em razão dos méritos de sua teoria dos germes, mas por um conjunto de fatores de ordem sociológica. Tais fatores fizeram com que Pasteur, e não Pouchet (que defendia a tese da geração espontânea), viesse a ser acolhido pela comunidade científica. A implicação desta tese é a de que hoje poderíamos estar reverenciando Pouchet ao invés de Pasteur. Kuhn certamente não concordaria com tal implicação (como, de resto, ninguém de bom senso), mas ela é uma decorrência natural de sua tese de o que se passa no interior da comunidade científica fazer parte da natureza do conhecimento científico.

16 Veja-se Philosophical darwinism. On the origin of knowledge by means of natural selection. London, Routledge and Kegan Paul, 1993. Esta expressão (the lure of sociology) merece uma qualificação para evitar mal entendidos. Uma sociologia do conhecimento que busque explicar por que certas teorias são produzidas em certos lugares e não em outros, ou por que são bem recebidas em certos lugares e rejeitadas em outros, ou ainda por que são ou não prontamente aceitas é muitíssimo bem vinda. A resposta para todas estas questões requer muitas vezes um exame das maneiras pelas quais os cientistas são socializados. O problema está em supor que as respostas para tais questões são relevantes para o entendimento da natureza dos problemas e da natureza das implicações embutidas nas referidas teorias. O "canto de sereia da sociologia" está em vincular a natureza dos problemas científicos e das implicações das teorias à autoridade de um grupo científico.

17 Em meu artigo Back to Darwin and Popper: criticism, migration of piecemeal conceptual schemes and the growth of knowledge (Philosophy of the Social Sciences, v. 27, n. 2, p. 157-179, 1997), mostro como Popper é repetidamente evasivo a este respeito.

18 Em seu artigo Lógica da descoberta ou psicologia da pesquisa? (In Lakatos \& Musgrave A crítica e o desenvolvimento do conhecimento, São Paulo, Cultrix, 1979, p. 6, nota de pé de página 5), Kuhn afirma: "Ambos [Kuhn e Popper] insistimos em que a fidelidade a uma tradição desempenha papel essencial no desenvolvimento científico. Ele [Popper] escreveu, por exemplo, 'quantitativa e qualitativamente a fonte mais importante de nosso conhecimento - tirando o conhecimento inato - é a tradição"'. Contra isto devo objetar que do fato da tradição ser uma fonte primordial de conhecimento não se segue que a fidelidade a uma tradição seja primordial para o desenvolvimento científico.

19 A estrutura das revoluções científicas, cit., p. 102.

Renan Springer de Freitas é professor da Universidade Federal de Minas Gerais. E-mail: Springer@dedalus.lcc.ufmg.br 